\title{
Baraj Rezervuarlarında Heyelanlardan Kaynaklanacak İki Dalga Özelliklerinin Ampirik İlişkilerle Değerlendirilmesi: Borçka Barajı Örneği
}

\author{
Hakan Ersoy ${ }^{1 *} \oplus$, Murat Karahan ${ }^{1} \oplus$, Hasan Hüseyin Öztürk ${ }^{2} \odot$ \\ ${ }^{1}$ Karadeniz Teknik Üniversitesi, Mühendislik Fakültesi, Jeoloji Mühendisliği Bölümü, 61080, Trabzon. \\ ${ }^{2}$ Devlet Su İşleri 26. Bölge Müdürlüğü, 08000, Artvin.

\section{Özet}

Bu çalıșmada Borçka Baraj Rezervuarında baraj gövdesine $4 \mathrm{~km}$ uzaklıkta bulunan paleo-heyelan malzemesinin aktif hale gelmesi durumunda oluşacak itki dalgalarının çevresel etkilerinin ampirik ilişkiler kullanılarak belirlenmesi amaçlanmıştır. Çalı̧̧mada, heyelan malzemesine ait farklı kalınlık ve genişlik değerleri dikkate alınarak, 0.5 ile 1 milyon metreküp arasında değişen hacimlerde malzemenin rezervuara akması durumu için 3 farklı senaryo geliştirilmiştir. Heyelan kaynakl dalganın rezervuarda her yöne dairesel olarak yayılacă̆ı belirlenmiş, dalga özellikleri 3 boyutlu ampirik yaklaşımlarla değerlendirilmiştir. Farklı senaryolar için, dalga hızının 27.1 ile $27.7 \mathrm{~m} / \mathrm{s}$ arasında değișeceği, en yüksek hız değeri için karșı kıyıya ulașacak dalga yüksekliğinin 23 metre olacağı ve bu dalganın karşı kıyıda yamaç boyunca 42.3 metre yükseleceği hesaplanmıştır. En düşük dalga hızı değeri için ise dalga yüksekliği $18.5 \mathrm{~m}$ ve yamaç boyunca ilerleme yüksekliği ise 32.5 metre olacaktır. Baraja ait 4 metrelik dalga payı değeri dikkate alındiğında, rezervuar boyunca ilerleyerek baraj gövdesine ulaşacak dalganın gövde için bir tehlike oluşturmayacağı belirlenmiştir. Basit rezervuar geometrileri ve kısa mesafeler için heyelan kaynaklı dalga özelliklerinin hesaplanmasında ampirik eşitliklerin kullanılması önerilirken, kompleks rezervuar geometrileri için mutlaka 3 boyutlu sayısal modellerin kullanılması, bu modellerde ise sayısal tabanlı yamaç duraylılık analizleri uygulanarak hesaplanacak heyelan hacmi değerinin kullanılması gerekliliği göz ardı edilmemelidir.

\section{$\underline{\text { Anahtar Sözcükler }}$}

Heyelan, Rezervuar, Dalga, Borçka Baraj1

\section{Assessment of landslide generated impulse waves in dam reservoirs using empirical relations: a case study on Borçka Dam}

\begin{abstract}
The aim of this study is to investigate environmental effects of impulse waves originated from reactivation of a paleo-landslide located $4 \mathrm{~km}$ far from the dam body in Borçka Dam reservoir using empirical relations. Considering different values of landslide width and thickness, 3 different scenarios were defined for the slide of landslide material in volumes ranging from 0.5 to 1 million cubic meters. The wave propagation in the reservoir was defined as radially, and properties of landslide generated impulse waves were evaluated using 3D empirical approaches. For different scenarios, it is determined that the wave height values range between 27.1 and $27.7 \mathrm{~m} / \mathrm{s}$, the wave height value for opposite shore reaches $23 \mathrm{~m}$ and run-up height value is $42.3 \mathrm{~m}$ for highest wave celerity value. The values of wave height and run-up height were calculated as $18.5 \mathrm{~m}$ and $32.5 \mathrm{~m}$ respectively for lowest wave celerity value. Considering the 4-meter freeboard for the dam, it was determined that the wave propagating through the reservoir and reaching the dam body would not create a danger for the body. Empirical equations can be used for the calculation of landslide-induced wave characteristics for simple reservoir geometries and short distances. But 3D numerical models should be preferred for complex reservoir geometries, and the need to use the landslide volume value to be calculated by applying numerical based slope stability analyzes should not be ignored in these models.
\end{abstract}

$\underline{\text { Keywords }}$

Landslide, Reservoir, Wave, Borçka Dam

\section{Giriş}

İtki dalgaları; buzul hareketleri, çı̆̆ oluşumları, kaya düşmeleri veya heyelanların baraj rezervuar alanlarında veya göl gibi doğal su kütlelerinde darbe etkisiyle oluşturdukları dalgalardır. İtki dalgalarının oluşmasında etkili olan bu doğa olayları çoğunlukla deprem ve iklimsel faktörler tarafından tetiklenmektedir. Deniz gibi büyük su kütlelerinde oluşan itki dalgaların birçoğunun etkisi hissedilemeyecek kadar küçük olsa da dünya ölçeğinde kayıtlara geçmiş yıkıcı etkilere sahip örnekler de mevcuttur. Heyelanların oluşturduğu itki dalgalarına en çarpıcı örnek 9 Temmuz 1958 tarihinde Alaska'da meydana gelen ve dünya üzerinde oluşan en büyük dalga olarak kayıtlara geçmiş itki dalgasıdır. 
Alaska Fayının kırılmasıyla gelişen bir deprem, Lituya Körfezi'nin kuzeydoğu kıyısında bulunan yaklaşık 40 milyon metreküp kaya kütlesinin 950 metre yükseklikten körfez sularına düşmesine neden olmuş ve darbe etkisiyle oluşan 524 metre yüksekliğindeki itki dalgası ana kaya üzerindeki metrelerce kalınlıktaki toprak örtüsünü kazıyarak körfez boyunca milyonlarca ağacın kökünden sökülmesine neden olmuştur. Yerleşimin olmadığı, doğal bir körfezde meydana gelen bu olayda 5 kişi hayatını kaybetmiştir. Tarihte baraj rezervuar alanlarında gelişen heyelan kaynaklı itki dalgalarının çok daha yıkıcı etkilere neden olduğu bilinmektedir. Dünya üzerinde kayıtlara geçen büyük baraj yıkılmaların yaklaşık \%10'unda baraj rezervuar alanlarındaki heyelanların etkili olduğu bilinmektedir (Ertunç ve Çetin 1999). Araştırmalar bu heyelanların genel olarak depremlerin etkisiyle, ani ve şiddetli yağışlara ve/veya rezervuarlardaki ani su değişimlerine bağlı olarak geliştĭgini göstermektedir (Riemer 1995). 1963 yılında İtalya'da Vajont Barajı rezervuar alanında meydana gelen bir heyelanın oluşturduğu itki dalgaları rezervuar heyelanlarının yıkıcı etkileriyle ilgili en çarpıcı örnektir. Vadi yamacındaki hidrostatik su basıncındaki ani değişimlerin neden olduğu heyelan 250 metre yüksekliğinde bir dalga oluşturmuş, oluşan dalga barajı aşarak mansap tarafinda bulunan birçok kasabayı etkileyerek yaklaşık 2000 kişinin hayatını kaybetmesine neden olmuştur (Zhang vd. 2010). Ülkemizde ise 2018 yılında Mardin'in Derik ilçesinde aşırı yağışlara bağlı olarak ilçe merkezine 24 km uzaklıkta bulunan Bayır Köyü ve çevresinde meydana gelen heyelanların toprak/kaya dolgu baraj gövdesini yıkması bu konu ile ilgili en güncel örnek olarak verilebilir. 3 köy ile 2 mezradaki tarım arazilerinin tamamının zarar görmesiyle sonuçlanan vakada can kaybı yaşanmamıştır.

Dünya ölçeğinde yaşanan benzer birçok felaketten sonra, barajların inşa edileceği bölgelerde bulunan heyelanların oluşum mekanizmasının ve duraylılığının araştıııldığı çalışmalara verilen önem artmıştır. Baraj gövde inşasının yapıldığı alanlarda yapılan çalışmalara ek olarak baraj rezervuar alanlarında bulunan heyelan alanları da detaylı olarak incelenmeye başlanmıştır. Fakat bu heyelanların aktif hale gelmesi sonucunda oluşacak itki dalgalarının rezervuar kıyısına ve baraj gövdesine etkilerinin belirlenmesine yönelik çalışmalar günümüzde dahi ihmal edilmektedir. Son 50 yıl içerisinde birçok araştırmacı tarafından deprem kaynaklı tsunamilerin yayılımı ve oluşum mekanizması üzerine araştırmalar yapılmış olsa da heyelan kaynaklı dalgalar üzerine yapılan çalışmalar ancak son 20-25 yıl içerisinde önem kazanmaya başlamıştır (Ramsden 1996; Fritz vd. 2004; Heller 2007; Akgün 2011; Kaczmarek vd. 2015; Yin vd. 2016; Ersoy vd. 2019).

Bu çalışma kapsamında da Artvin ili sınırları içerinde kil çekirdekli kaya dolgu baraj olarak inşa edilmiş Borçka barajının $4 \mathrm{~km}$ membasında yer alan bir paleo-heyelanın (Şekil 1) aktif hale gelmesi durumunda oluşacak itki dalgalarının çevresel etkileri ampirik yaklaşımlar kullanılarak incelenmiştir. Kret uzunluğu $728 \mathrm{~m}$ olan barajın talvegten yüksekliği 86 m'dir. Kret kotu 189 m, maksimum işletme seviyesi $185 \mathrm{~m}$ olan barajda dalga payı 4 metredir.

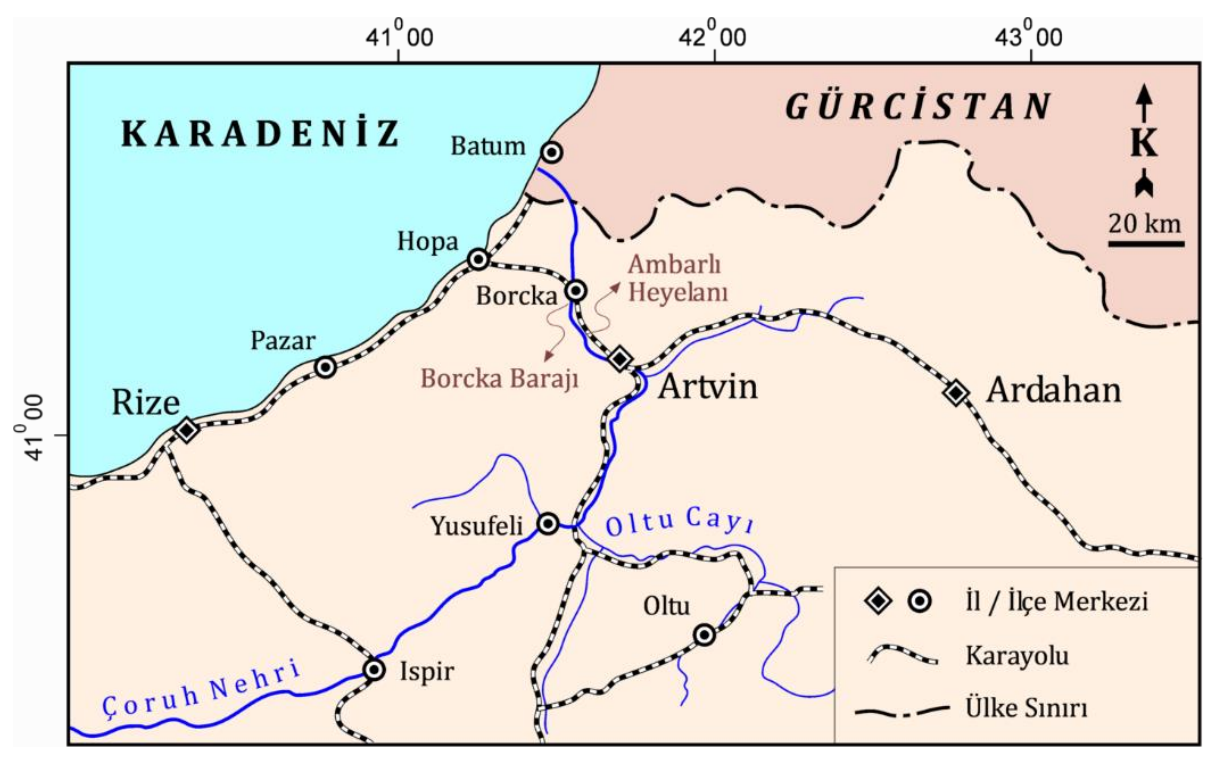

Şekil 1: Çalışma alanı ve çevresinin yer bulduru haritası

\section{Heyelan Kaynaklı İtki Dalgalarının Oluşumu ve Yayılımı}

Heyelan kaynaklı itki dalgalarının oluşum mekanizması 3 ayrı fazda ele alınmaktadır (Şekil 2). Bunlar; (1) heyelan etkisiyle dalga oluşumu, (2) dalganın rezervuarda yayılımı ve (3) dalganın topografik bir yüzeye ve/veya baraj gövdesine çarpması şeklinde sıralanmaktadır. İtki dalgalarından kaynaklanacak etkilerin belirlenmesinde yukarıda sıralanan 3 ayrı faz, bir bütün olarak değerlendirilmekte, ancak farklı modellerle analiz edilmektedir.

Heyelan sonucunda oluşacak darbenin etkisi heyelan malzemesinin hacmine, kalınlığına, darbe hızına ve yamaç eğimine bağlıdır. Bu nedenle çalışmaların temelini heyelan malzemesinin hacminin, yanal ve düşey devamlılığının belirlenmesi aşaması oluşturmaktadır. Dalga yayılımın ve etkisinin gerçeğe yakın bir şekilde modellenmesi jeolojik ve jeoteknik verilerin doğruluğuna bağlıdır. 
İtki dalgasının fiziksel özellikleri ve yayılımı heyelan malzemesinin darbe etkisine, rezervuar şekline, derinliğine ve dalganın yayılım istikametine bağlıdır. İtki dalgalarının rezervuar kıyısında veya baraj gövdesindeki etkisi ise su derinliğine, dalga hızına, dalga yüksekliğine, karşı kıyı ve/veya baraj gövde eğimine bağlı olarak değişmektedir (Şekil 2).

Heyelan
malzemesi

Şekil 2: Yatay bir rezervuar üzerinde bir itki dalgasına ait üç ayrı faz (i: heyelan darbesi ile dalga oluşumu, ii: dalganın rezervuardaki yayılımı, iii: dalganın karşı kıyıda ve/veya baraj gövdesi üzerinde ilerlemesi, Heller vd. 2009)

İtki dalgalarının yayılımı genel olarak (i) doğrusal ve (ii) dairesel olmak üzere iki ana başlıkta toplanmaktadır (Heller vd. 2009). Kayan heyelan malzemesinin genişliği rezervuar genişliğinden daha büyük ise itki dalgaları rezervuar boyunca doğrusal olarak yayılırlar. Bu durumda yanal yayılma söz konusu değildir (Şekil 2a). Bazı durumlarda özellikle rezervuarın geniş olduğu bölgelerde kayan malzemenin genişliği rezervuara göre çok küçük olur. Bu durumda oluşan dalga darbe bölgesinden bağımsız olarak dairesel şekilde yayılır (Şekil $2 b$ ve d). Dalga yayılımı doğrudan rezervuar geometrisi ile ilişkili olup, her iki durumda itki dalgalarının fiziksel özellikleri ve dalgalardan kaynaklanacak etkiler farklı modellerle analiz edilmektedir.

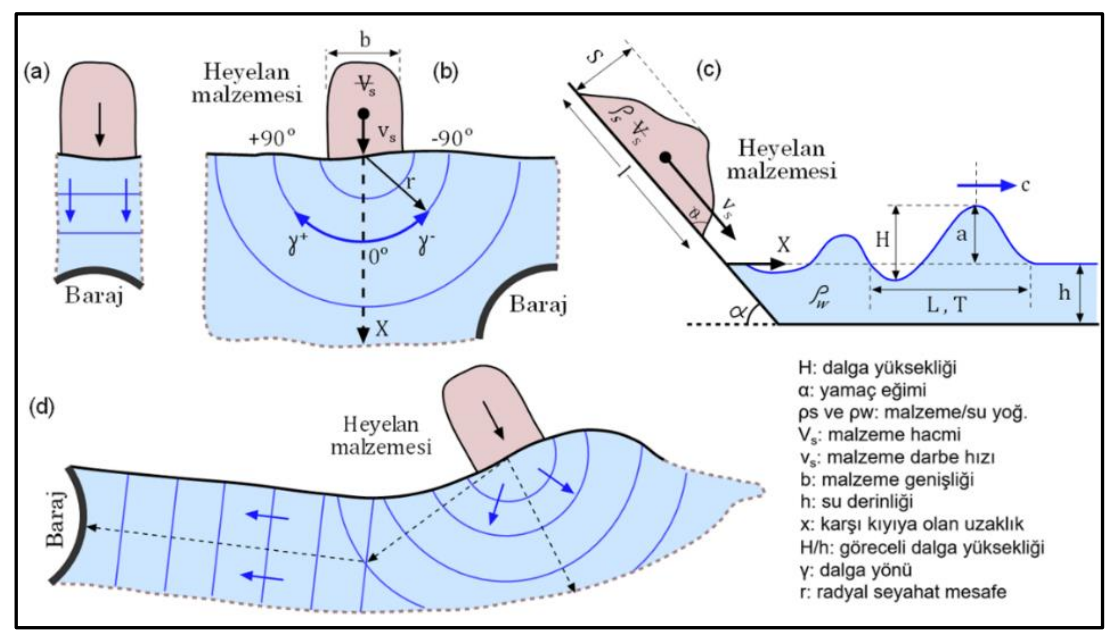

Şekil 3: Heyelan kaynaklı itki dalgalarının yayılım doğrultusu ve fiziksel özellikleri (a: dar ve uzun rezervuarda lineer dalga yayılımı, b: geniş rezervuarda dairesel dalga yayılımı, c: heyelan malzemesinin ve oluşan dalganın fiziksel özellikleri, d: karmaşık geometriye sahip rezervuarlarda dairesel ve doğrusal dalga yayılımı, Heller vd. 2009)

İtki dalgaların fiziksel özelliklerinin belirlenmesine yönelik 5 farklı yöntem önerilmektedir (Heller vd. 2009). Bunlar; (1) arazi verilerden elde edilen ampirik eşitliklerin kullanımı (Fritz 2002; Quecedo vd. 2004), (2) analitik değerlendirmeler, (3) laboratuvar deneylerinden elde edilen ampirik eşitliklerin kullanımı (Hughes 1993; Heller vd. 2008), (4) nümerik benzetim modellerine (simülasyonlara) dayalı modeller (Grilli vd. 2002; Montagna vd. 2011; Gabl vd. 2015) ve (5) prototip özel modeller üzerinde yapılan deneyler şeklinde sıralanabilir. Tablo 1'de farklı kriterlere göre karşılaştırılan yöntemler özetlenmiştir.

Arazi verilerinden yararlanılarak oluşturulan ampirik eşitlikler kullanılarak yapılan analizler zaman, maliyet ve girdi parametrelerinin basitliği düşünüldüğünde değerlendirme kolaylığı açısından kullanışlı yöntemlerdir. Özellikle basit geometriye sahip rezervuarlarda kısa mesafeler için tutarlı sonuç vermelerine rağmen, uzun mesafeler ve karmaşık rezervuar geometrilerinde prototip model deneyler ve/veya nümerik simülasyonlar tercih edilmelidir. 
Tablo 1: Heyelan kaynaklı dalga özelliklerinin tahmininde kullanılan yöntemlerin karşılaştırılması (Heller vd. 2009)

\begin{tabular}{|c|c|c|c|c|c|}
\hline Ölçütler & Yöntem (1) & Yöntem (2) & Yöntem (3) & Yöntem (4) & Yöntem (5) \\
\hline Sonuçların kalitesi & Kaba tahmin & Kaba tahmin & Tahmin & Tahmin-kesin & Kesin \\
\hline Zaman & $\mathrm{Az}$ & $\mathrm{Az}$ & $\mathrm{Az}$ & Fazla-Çok fazla & Çok fazla \\
\hline Maliyet & $\mathrm{Az}$ & $\mathrm{Az}$ & $\mathrm{Az}$ & Fazla-Çok fazla & Çok fazla \\
\hline Kullanıcı & Mühendis & Mühendis & Mühendis & Uzman & Mühendis \\
\hline Girdi parametrelerinin önemi & Orta & $\mathrm{Az}$ & Orta & Yüksek & Yüksek \\
\hline
\end{tabular}

\section{Materyal ve Metot}

\subsection{Girdi parametrelerinin ve sınır koşullarının belirlenmesi}

Heyelan kaynaklı itki dalgalarının özelliklerinin tahminine yönelik birçok eşitlik geliştirilmiştir (Chow 1960; Müller 1995; Synolakis 1987; Huber ve Hager 1997; Panizzo vd. 2005b; Heller vd. 2009). Ancak hangi eşitlik tercih edilirse edilsin, dalga yüksekliği, hızı, periyodu ve uzunluğu gibi fiziksel özellikler belirlenirken sınır koşullarının ve girdi parametrelerinin doğru şekilde tanımlanması gerekmektedir. İlgili formüller dalganın lineer veya dairesel olması durumunda değişse de hemen hemen her eşitlikte benzer girdi parametreleri kullanılmaktadır. Bunlar; (1) heyelan darbe hızı $\left(\mathrm{V}_{\mathrm{s}}\right),(2)$ heyelana ait kayma yüzeyi açısı (veya yamaç eğimi) $(\alpha)$, (3) heyelan hacmi $\left(\bigvee_{\mathrm{s}}\right)$, (4) heyelan kalınlığı (s), (5) heyelan genişliği (b), (6) heyelan malzemesinin yoğunluğu $\left(\rho_{\mathrm{s}}\right)$, (7) heyelan malzemesinin porozitesi (n) ve (8) su derinliği (h) şeklinde sıralanabilir.

$\mathrm{Bu}$ parametreler, detaylı saha ve laboratuvar çalışmaları (sondaj uygulaması, yerinde arazi deneyi, jeofizik ölçümler ve fotogrametrik çalışmalar) ile belirlenebilir. Yapılacak duraylılık analizlerinde ise kritik kayma yüzeyi belirlenerek olası heyelanın hacmi öngörülebilir. Ancak bu çalışmada olası bir heyelan durumunda itki dalgalarının özelliklerine yönelik ön bilgi edinilmesi amacıyla saha çalışmaları ve duraylılık analizleri yapılmaksızın, olası heyelan malzemesine ait farklı kalınlık ve genişlik değerleri dikkate alınarak, 0.5 ile 1 milyon metreküp arasında değişen hacimlerde malzemenin rezervuara akması durumu için 3 farklı senaryo geliştirilmiştir. Farklı senaryolar için değişken parametreler Tablo 2'de, sabit parametreler Tablo 3'de verilmiştir.

Tablo 2: Farklı senaryolar için girdi parametrelerindeki değişimler

\begin{tabular}{|l|c|c|c|}
\hline Sınır Koşulları & Senaryo 1 & Senaryo 2 & Senaryo 3 \\
\hline Heyelan malzemesi kalınlığı $(\mathrm{s})$ & $20 \mathrm{~m}$ & $25 \mathrm{~m}$ & $30 \mathrm{~m}$ \\
\hline Heyelan malzemesi genişliği $(\mathrm{b})$ & $100 \mathrm{~m}$ & $125 \mathrm{~m}$ & $150 \mathrm{~m}$ \\
\hline Yer değiştirme kot farkı $\left(\Delta \mathrm{Z}_{\mathrm{sc}}\right)$ & $70 \mathrm{~m}$ & $70 \mathrm{~m}$ & $70 \mathrm{~m}$ \\
\hline Heyelan malzemesi hacmi $\left(\mathrm{V}_{\mathrm{s}}, \mathrm{m}^{3}\right)$ & 500.000 & 750.000 & 1.000 .000 \\
\hline Heyelana ait kayma yüzeyi açısı $(\alpha)$ & 30 & 30 & 30 \\
\hline
\end{tabular}

Tablo 3: Dalga özellikleri belirlenmesinde kullanılan bu çalışma için sabit olan girdi parametreleri

\begin{tabular}{|l|c|c|c|}
\hline Girdi parametreleri & Darbe bölgesi & Karşı kıyı & Baraj \\
\hline Yayılma mesafesi $(\mathrm{x}, \mathrm{r})$ & 0 & $400 \mathrm{~m}$ & $4000 \mathrm{~m}$ \\
\hline Yayılma açısı $(\gamma)$ & $0-90^{\circ}$ & $0^{\circ}$ & $80^{\circ}$ \\
\hline Su derinliği $(\mathrm{h})$ & $60 \mathrm{~m}$ & $60 \mathrm{~m}$ & $80 \mathrm{~m}$ \\
\hline Karşı kıyı/baraj gövde eğimi $(\beta)$ & - & $60^{\circ}$ & $70^{\circ}$ \\
\hline
\end{tabular}

\subsection{Ampirik eşitliklerin değerlendirilmesi}

Yerleşim alanları için meydana gelecek riskler ve baraj güvenliği dikkate alındığında, heyelan kaynaklı itki dalgalarının yükseklik, hız vb. gibi özelliklerinin belirlenmesi çok önemlidir. Heyelan malzemesinin çarpma hızı ise bu parametreler içinde en etkin parametre olarak kabul edilmektedir (Ersoy vd. 2019). Bu nedenle çalışmanın ilk aşamasında rezervuara kayacak malzeme hızı (heyelan darbe hızı) Körner (1976) tarafından önerilen eşitlik kullanılarak hesaplanmıştır.

$v_{s}=\sqrt{2 g \Delta Z_{s c}(1-\tan \delta \cot \alpha)}$ 
burada;
$\mathrm{v}_{\mathrm{s}}(\mathrm{m} / \mathrm{s}) \quad$ : kayma (heyelan) hızı
$\mathrm{g}\left(\mathrm{m} / \mathrm{s}^{2}\right) \quad$ : yer çekimi ivmesi $\left(9.81 \mathrm{~ms}^{-2}\right)$
$\Delta \mathrm{Z}_{\mathrm{sc}}(\mathrm{m}) \quad$ : heyelan malzemesinin suya çarpana kadar düşeyde kat ettiği kot farkı $(70 \mathrm{~m})$
$\alpha\left({ }^{\circ}\right) \quad$ : heyelana ait kayma yüzeyi açısı (veya yamaç eğimi) $\left(30^{\circ}\right)$
$\delta\left({ }^{\circ}\right) \quad$ : yatak sürtünme açısı (veya malzeme içsel sürtünme açısı, $25^{\circ}$ olarak kabul edilmiştir)

Çalışmada kullanılacak eşitliklerin belirlenmesinde en önemli parametre dalga yayılım şeklidir. Maksimum heyelan genişliği $(150 \mathrm{~m})$, minimum yayılma mesafesinden $(400 \mathrm{~m})$ çok küçük olduğu için bu çalışma kapsamında itki dalgalarının radyal olarak yayılacağı belirlenmiş (Şekil 3b ve d) ve 3 boyutlu prototip deneyler kullanılarak üretilen ampirik eşitlikler tercih edilmiştir. Çalışmada farklı 3 senaryo dikkate alınmış (Tablo 2) itki dalga yüksekliği Noda (1970) ve Heller (2007), karşı kıyıda ilerleme yüksekliği Synolakis (1987) ve Müller (1995) tarafindan önerilen eşitlikler yardımıyla hesaplanmıştır.

$$
\begin{array}{ll}
H(r, \gamma)=\left(\frac{3}{2}\right) P^{4 / 5} \cos ^{2}\left(\frac{2 \gamma}{3}\right)\left(\frac{r}{h}\right)^{-2 / 3} h & \text { (Huber ve Hager 1997; Heller 2007) } \\
H=F x s & \text { (Noda 1970) } \\
R=1.25\left(\frac{H}{h}\right)^{5 / 4}\left(\frac{H}{L}\right)^{-3 / 20}\left(\frac{90^{o}}{\beta}\right)^{1 / 5} h & \text { (Müller 1995) } \\
R / h=2.831(\cot \beta)^{0.5}(H / h)^{1.25} & \text { (Synolakis 1987) }
\end{array}
$$

burada;

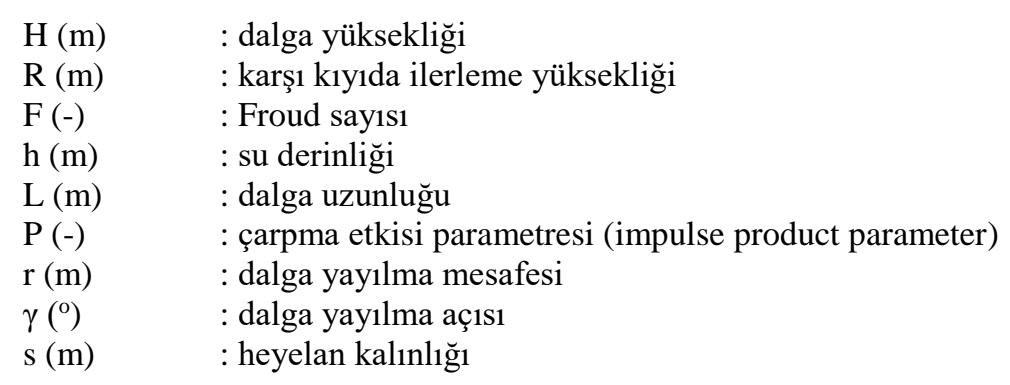

Heyelan kaynaklı itki dalgasının karşı kıyıda ilerleme yüksekliğinin belirlenmesi için dalga periyot ve dalga uzunluk değerine ihtiyaç duyulmaktadır. Çalışma kapsamında bu değerler Heller (2007) tarafından önerilen eşitlikler kullanılarak belirlenmiştir.

$$
\begin{aligned}
& T_{M}=9 P^{1 / 2}(h / g)^{1 / 2} \\
& L_{M}=T_{M} c
\end{aligned}
$$

burada;

$$
\begin{array}{ll}
\mathrm{T}_{\mathrm{M}}(\mathrm{s}) & : \text { dalga periyodu } \\
\mathrm{L}_{\mathrm{M}}(\mathrm{m}) & \text { : dalga uzunluğu }
\end{array}
$$

İtki dalga yüksekliği kadar yayılma hızının belirlenmesi de özellikle erken uyarı sistemlerinin geliştirilmesi açısından önemlidir. Bu çalışmada özellikle 1800'li yılların başlarında geliştirilen ve günümüze kadar geçerliliğini koruyan dalga hız eşitliği kullanılmıştır.

$c=[g(h+a)]^{1 / 2}$

burada;

$$
\begin{array}{ll}
\mathrm{c}(\mathrm{m} / \mathrm{s}) & : \text { dalga hızı } \\
\mathrm{g}\left(9.81 \mathrm{~ms}^{-2}\right) & : \text { yer çekimi ivmesi }\left(9.81 \mathrm{~ms}^{-2}\right)
\end{array}
$$


h (m) : su derinliği

a (m) : dalga genliği (4H/5, Heller vd. 2009)

\section{4. Çalışma Alanı ve Çevresinin Jeolojisi}

Doğu Pontidler birçok araştırmacı tarafindan tektonik, magmatik, sedimantolojik özelliklerine göre farklı zonlara ayrılmıştır. Özsayar vd. (1981) tarafından iki ana zona ayrılan Doğu Pontidler, Bektaş vd. (1995) tarafından Kuzey, Güney ve Eksen Zonu olarak üçe ayrılmıştır. Kuzey Zon volkanik kayaçlar ve granitik intrüzyonlarla karakterize edilirken, Güney Zon metamorfik masifler, granitik kayaçlar ve baskın olarak sedimanter kayaçlar ile karakterize edilir. Kuzey Zon içerisinde yer alan çalışma alanında Eosen yaşlı Kabaköy Formasyonu'na ait volkanik kayaçlar yüzeylenme vermektedir (Şekil 4). Dik topografya ile karakterize olan bu kayaçlarda yer yer kaya düşmesi olaylarına rastlanılmıştır. Güney kesimlerde ise çok dar alanlarda kireçtaşı, kumtaşı, kiltaşı ve marnlardan oluşan Üst Kretase-Paleosen yaşlı Cankurtaran Formasyonu bulunmaktadır. Düşük eğimli bölgelerde yüzeylenme veren birim içinde gelişmiş paleo-heyelanlar gözlenmiştir. Çalışma konusunu oluşturan ve Ambarlı Köyü yakınlarında bulunan bir paleo-heyelanın topuğu Borçka Baraj Rezervuarı içerisinde kalmaktadır. Yapılan arazi incelemeleri sonucunda eski bir heyelana ait 10-12 metre yüksekliğinde heyelan aynası net olarak gözlenmiştir. Yanal yönde devam eden ikinci aynalar göl alanına kadar devam etmektedir (Şekil 5). Üzerinde yerleşim olan bölgede aktif bir hareket söz konusu değildir.

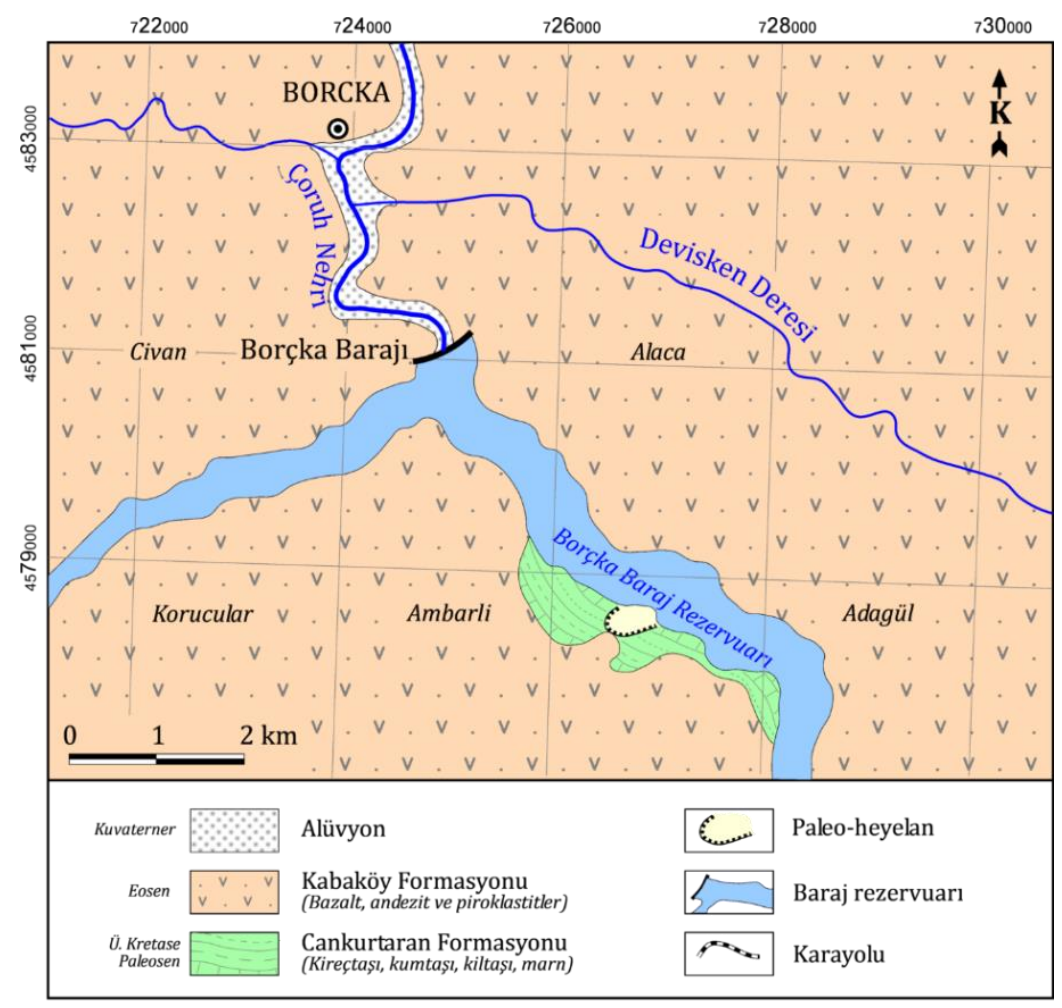

Şekil 4: Çalışma alanı ve çevresinin jeoloji haritası (Güven (1993)'den değiştirilerek) 


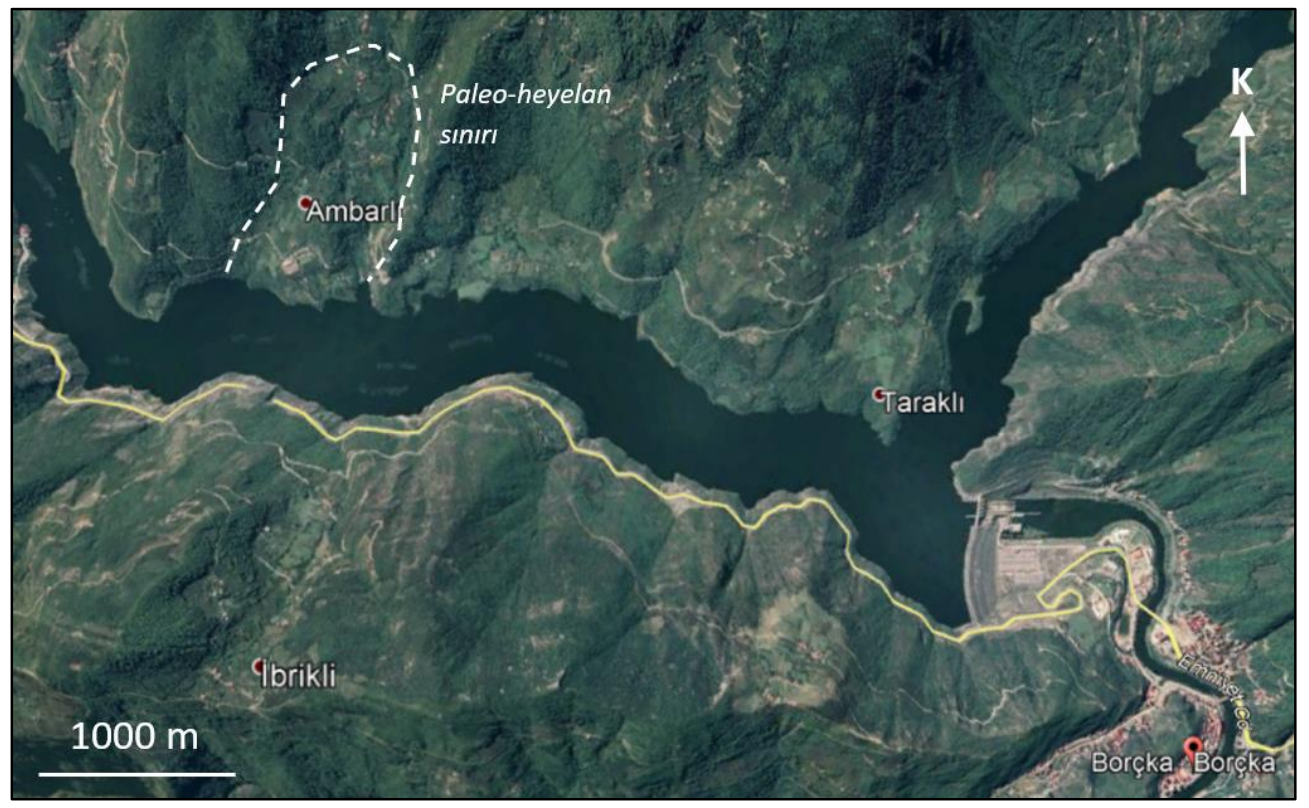

Şekil 5: Ambarlı Köyü paleo-heyelanının uydu görüntüsündeki yeri

\section{Heyelan Kaynaklı İtki Dalgalarının Özellikleri}

İtki dalgalarının fiziksel özelliklerinin belirlenmesine yönelik geliştirilen eşitlikler genellikle laboratuvarda fiziksel modeller üzerinde yapılan deneylere dayandığı için, bu eşitliklerin kullanımında laboratuvar çalışmalarında belirlenen sınır koşullara uyulması gerekmektedir. $\mathrm{Bu}$ nedenle çalışma kapsamında, ampirik eşitliklerin sınırlamaları ortaya koyulmuş ve çalışma bu ölçüde sürdürülmüştür. Tablo 4'te bu çalışmada hesaplanan değerler ile ampirik çalışmalarda öngörülen sınır değerleri karşılaştırılması verilmiştir.

Tablo 4: Ampirik formüllerin bu çalışma için kullanım sınırlamaları

\begin{tabular}{|l|c|c|c|}
\hline Özellik & Değer & Sınırlama aralı̆̆ $($ Heller vd. 2009) & Yeterlilik \\
\hline Froud numarası $(\mathrm{F})$ & 0.95 & $0.86 \leq \mathrm{V}_{\mathrm{s}} /(\mathrm{g} \mathrm{x} \mathrm{h})^{1 / 2} \leq 6.83$ & Evet \\
\hline Nispi heyelan malzemesi kalınlığı $(\mathrm{S})$ & $0.33-0.50$ & $0.09 \leq \mathrm{s} / \mathrm{h} \leq 1.69$ & Evet \\
\hline Nispi heyelan malzemesi hacmi $\left(\vee_{\mathrm{s}}\right)$ & $1.39-1.85$ & $0.05 \leq \mathrm{\vee}_{\mathrm{s}} /\left(\mathrm{b} \mathrm{h} \mathrm{h}^{2} \leq 5.94\right.$ & Evet \\
\hline Heyelana ait kayma yüzeyi açısı $(\alpha)$ & 30 & $30^{0} \leq \alpha \leq 90^{0}$ & Evet \\
\hline Nispi heyelan malzemesi kütlesi $(\mathrm{M})$ & $2.78-3.70$ & $0.11 \leq \mathrm{M}=\rho_{\mathrm{s}} \mathrm{\vee}_{\mathrm{s}} /\left(\rho_{\mathrm{w}} \mathrm{b} \mathrm{h}^{2}\right) \leq 10.02$ & Evet \\
\hline Nispi dalga yayılma mesafesi (karşı kıyı) $(\mathrm{X})$ & 6.7 & $2.7 \leq \mathrm{x} / \mathrm{h} \leq 59.7$ & Evet \\
\hline Nispi dalga yayılma mesafesi (baraj) $(\mathrm{R})$ & 50 & $5 \leq \mathrm{r} / \mathrm{h} \leq 30$ & Hayır \\
\hline
\end{tabular}

Tablo 4 incelendiğinde, bu eşitliklerin heyelan bölgesine $4 \mathrm{~km}$ uzaklıkta bulunan baraj gövdesine olan etkilerin belirlenmesi için gerekli sınır koşulları sağlamadığı görülmektedir. Bu nedenle çalışmada sadece heyelan çarpma (darbe) bölgesi ile heyelanın oluştuğu bölgenin karşı kıyısı için değerlendirmeler yapıllmıştır. Eşitlik 1-8 kullanılarak 3 farklı senaryoya göre elde edilen sonuçlar Şekil 6'da verilmiştir. 

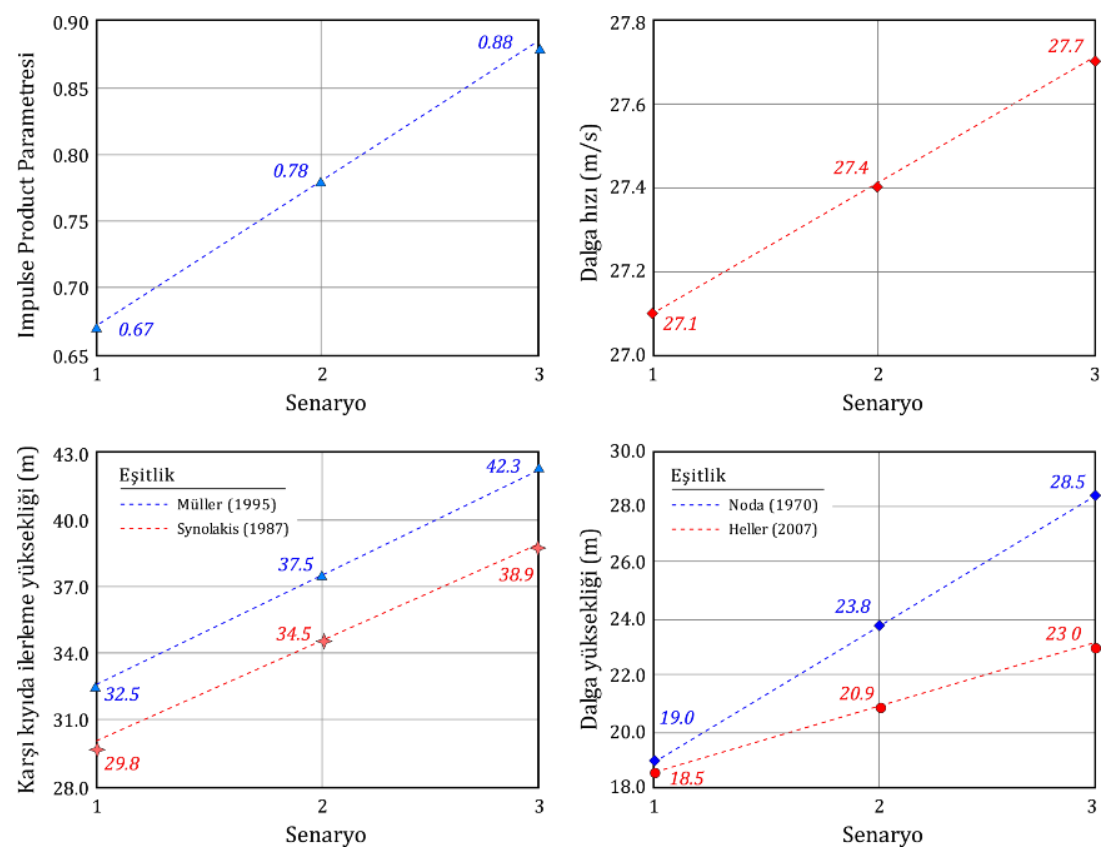

Şekil 6: Ampirik eşitliklere göre hesaplanan dalga özelliklerinin farklı senaryolara göre değişimi

Şekil değerlendirildiğinde heyelan kaynaklı dalga hızı değerinin Senaryo 1 koşulları dikkate alındığında $27.1 \mathrm{~m} / \mathrm{s}$, Senaryo 3 koşulları dikkate alındığında $27.7 \mathrm{~m} / \mathrm{s}$ olduğu görülmektedir. Senaryo 1 için karşı kıyıda oluşacak dalga yükseklikleri hesaplandığında Heller (2007) tarafından önerilen eşitliğe göre 18.5 m, Noda (1970) tarafından önerilen eşitliğe göre 19.0 m yüksekliğinde bir dalganın etkili olacağı görülmektedir. Senaryo 1 için her iki araştırmacı tarafından önerilen eşitliklerle bulunan değerlerin çok yakın olduğu görülse de (0.5 metrelik fark), heyelan malzeme hacimdeki 2 kat artış (Senaryo 3) farklı eşitlikler kullanılarak belirlenen dalga yükseklik değerlerinde yaklaşı 5 metrelik bir farka neden olmaktadır. Bu durumda karşı kıyıya ulaşacak dalga yüksekliği sırasıyla 23 m ve 28.5 m olacaktır. Karşı kıyıya çarpacak dalganın karşı kıyıda ilerleme yüksekliği değerleri ise Müller (1995) tarafından önerilen eşitliğe göre Senaryo 1 için 32.5 m, Senaryo 2 için 42.3 m olacaktır. Bu değerler, Synolakis (1987) tarafından önerilen eşitliğe göre ise farklı senaryolar için $29.8 \mathrm{~m}$ ve 38.9 m olarak hesaplanmıştır.

Baraj gövdesi için "rölatif yayılma mesafesi (R)" sınır değerlerin üstünde kalmaktadır. Bu nedenle çalışmada, bu değerin sınır değer içerisinde kalmasını sağlayacak yayılma mesafesi değerleri hesaplanmaya çalışılmıştır. Su derinliği değerinin rezervuar ortalama derinliği (heyelan ile gövde arasında) olarak (70 metre) kabul edilmesi durumunda; eşitliğin 2100 m yayılma mesafesi için sınır değer içerisinde kalacağı anlaşılmıştır. Bu nedenle heyelan bölgesinden 2000 metre mesafeye kadar her 250 metre uzaklık için dalga yüksekliği değerleri Senaryo 3 dikkate alınarak Heller (2007) tarafından önerilen eşitlik kullanılarak tekrar hesaplanmıştır (Tablo 5). Baraj gövdesine etkiyecek dalga yüksekliğinin değerlendirilmesinde Senaryo 3'ün dikkate alınmasının nedeni, bu senaryonun en kötü koşulu yani en yüksek değere sahip dalga yüksekliğini temsil etmesidir. Heyelan alanına 4000 metre uzaklıkta bulunan Borçka Barajı'nın dalga payı yüksekliği 4 metre olduğu için, baraj gövdesine doğru yayılan itki dalgasının 1250 metre mesafede bile baraj gövdesini aşamayacak kadar düşük yükseklikte olacağı anlaşılmıştır.

Tablo 5: Senaryo 3 dikkate alınarak "rölatif yayılma mesafesi” sınır değerleri dikkate alınarak baraj gövdesine doğru yayılan dalgaya ait farklı mesafeler için yükseklik değerleri

\begin{tabular}{|l|c|c|c|c|c|c|c|}
\hline Dalga Yayılma mesafesi (m) & $\mathbf{5 0 0}$ & $\mathbf{7 5 0}$ & $\mathbf{1 0 0 0}$ & $\mathbf{1 2 5 0}$ & $\mathbf{1 5 0 0}$ & $\mathbf{1 7 5 0}$ & $\mathbf{2 0 0 0}$ \\
\hline $\begin{array}{l}\text { Nispi dalga yayılma mesafesi (R) } \\
(5 \leq \mathrm{r} / \mathrm{h} \leq 30)\end{array}$ & 7.14 & 10.71 & 14.28 & 17.86 & 21.42 & 25.00 & 28.57 \\
\hline $\begin{array}{l}\text { Dalga yüksekliği (H) } \\
\text { Heller (2007) }\end{array}$ & 7.1 & 5.4 & 4.5 & 3.8 & 3.4 & 3.1 & 2.8 \\
\hline
\end{tabular}

\section{Sonuçlar ve Tartışma}

$\mathrm{Bu}$ çalışma kapsamında Artvin ili sınırları içerisinde ön yüzü beton kaplama kaya dolgu baraj olarak inşa edilmiş olan Borçka Barajı rezervuar alanında baraj gövdesine $4 \mathrm{~km}$ uzaklıkta bulunan bir paleo-heyelanın aktif hale gelmesi durumunda oluşacak itki dalgalarının rezervuar alanına ve baraja olan etkileri ampirik ilişkiler kullanılarak değerlendirilmiştir. 
Çalışma kapsamında paleo-heyelan malzemesinin yayılımı dikkate alınarak, 0.5 ile 1 milyon metreküp arasında değişen hacimlerde heyelan malzemesinin rezervuara hareket edeceği durumlar için 3 farklı senaryo geliştirilmiştir. Saha (sondaj uygulaması, jeofizik ölçümler) ve laboratuvar çalışmalarına başlamadan önce, bu çalışmalar için izlenecek yol (ölçüm sıklığı, derinliği vb.) hakkında ön ve hızlı bilgi etmeyi amaçlamak ise bu çalışmanın bir diğer amacıdır. Çalışmada elde edilen sonuçlar aşağıda maddeler halinde özetlenmiştir.

(1) Çalışmanın ilk aşamasında önerilen eşitliklerinin sınırlamalarını ortaya koymak için değerlendirmeler yapılmıştır. Parametreler arasında sayısal ilişkiye, heyelan ve rezervuar geometrisine dayanan bu değerlendirmeler sonucunda, oluşacak itki dalgasının radyal olarak yayılacağı ve ampirik eşitliklerin 2100 metrelik yayılma mesafesi boyunca anlamlı sonuçlar vereceği hesaplanmıştır. Bu nedenle ilgili eşitliklerin, 400 metre uzaklıktaki karşı kıyı ve yakın yamaçlar için tutarlı olduğu, $4000 \mathrm{~m}$ uzaklıktaki baraj gövdesi için kullanılamayacak olduğu belirlenmiştir.

(2) Yapılan değerlendirmelerde farklı senaryolar için dalga hızı, karşı kıyıya ulaşacak dalganın yüksekliği ve yamaç boyunca dalganın ilerleyeceği maksimum yükseklik değerleri hesaplanmıştır (Tablo 6)

Tablo 6: Farklı senaryolar için farklı araştırmacılar tarafından önerilen eşitliklere göre hesaplanan dalga özellikleri

\begin{tabular}{|l|l|c|c|c|}
\hline Fiziksel Özellikler & Eşitlikler & Senaryo 1 & Senaryo 2 & Senaryo 3 \\
\hline Dalga hızı (m/s) & Genel & 27.1 & 27.4 & 27.7 \\
\hline Dalga yüksekliği (karşı kıyı) (m) & Heller (2007) & 18.5 & 20.9 & 23.0 \\
& Noda (1970) & 19.0 & 23.8 & 28.5 \\
\hline Karş1 kıyıda ilerleme yüksekliği (m) & Müller (1995) & 32.5 & 37.5 & 42.3 \\
& Synolakis (1987) & 29.8 & 34.5 & 38.9 \\
\hline
\end{tabular}

(3) Heyelan kaynaklı itki dalgasının hızının farklı senaryolar için $27.1 \mathrm{~m} / \mathrm{s}$ ile $27.7 \mathrm{~s}$ arasında değiştiği Tablo 6'da görülmektedir. Heyelan malzeme hacminde iki kat artışa rağmen, oluşacak dalganın hızındaki \% 2'lik fark, rezervuara kayacak malzeme hacminin dalga hızında çok etkili olmadığını göstermektedir. Bu nedenle dalga özelliklerine dair başka bir çalışmanın yapılmaması durumunda bile, oluşacak dalganın 144-147 sn arasında baraj gövdesine ulaşacağının bilinmesi erken uyarı sistemlerinin geliştirilmesi açısından önemli bir bilgi olacaktır.

(4) Karşı kıyıya çarpacak dalganın yüksekliği Heller (2007) tarafından önerilen eşitliğe göre farklı senaryolar için $18.5 \mathrm{~m}$ ile $23.0 \mathrm{~m}$ arasında, Noda (1970) tarafından önerilen eşitliğe göre ise $19.0 \mathrm{~m}$ ile $28.5 \mathrm{~m}$ arasında değişmektedir. Düşük hacimlerde fark olmamasına rağmen, oluşacak heyelan hacmi arttıkça iki farklı eşitlikten elde edilen sonuçlardaki farkın büyümesi, Noda (1970) tarafından önerilen eşitliklerde heyelan kütlesinin dikkate alınmamasından kaynaklanmaktadır.

(5) Oluşacak dalganın karşı kıyıda ilerleme yüksekliği, farklı senaryolar dikkate alınarak Müller (1995) tarafından önerilen eşitlik kullanılarak $32.5 \mathrm{~m}$ ile $42.5 \mathrm{~m}$ arasında, Synolakis (1987) tarafından önerilen eşitlikler kullanılarak 29.8 ile $38.9 \mathrm{~m}$ arasında değiştiği belirlenmiştir.

(6) Eşitliklerin sınır değerler içinde kalma koşulu gözetilerek oluşacak dalganın heyelan alanından 1250 metre mesafede bile baraj dalga payından küçük olacağı $(\mathrm{H}: 3.8 \mathrm{~m}<$ baraj dalga payı: $4.0 \mathrm{~m}$ ) hesaplandığı için, 4000 metrelik rezervuar boyunca yayılacak dalganın baraj gövdesinde olumsuz bir etki oluşturmayacağı belirlenmiştir.

(7) Çalışmada elde edilen sonuçların yüksek değerler verdiği düşünülmektedir. Çünkü senaryolar belli kabullere göre tanımlanmıştır. Bu nedenle, çalışmanın ilerleyen aşamasında heyelan malzemesinin mühendislik özelliklerinin belirlenmesi amacıyla detaylı jeolojik ve jeoteknik çalışma yapılması, elde edilen veriler kullanılarak stabilite analizleri ile rezervuara kayacak heyelan malzemesinin hacminin daha detaylı belirlenmesi ve rezervuarın bütününün bir benzetim modeline (simülasyona) dayalı nümerik modellerle çözümlenmesi önerilmektedir.

\section{Teşekkür}

Yazarlar, çalışmaya katkı sağlayan Artvin 26. Bölge Müdürlüğü çalışanlarına ve makalenin incelenmesi aşamasında değerli katkılar sağlayan hakemlere teşekkür eder.

\section{Kaynaklar}

Akgün A., (2011), Assessment of possible damaged areas due to landslideinduced waves at a constructed reservoir using empirical approaches: Kurtun (North Turkey) Dam reservoir area, Natural Hazards and Earth System Science, 1, 1341-1350.

Bektaş O., Yılmaz C., Taslı K., Akdağ K., Özgür S., (1995), Cretaceous rifting of the eastern Pontide carbonate platform (NE Turkey): the formation of carbonates breccias and turbidites as evidence of a drowned platform. Geologia, 57 (1-2), $233-244$.

Chow V.T., (1960), Open channel hydraulics, McGraw-Hill, New York.

Ersoy H., Karahan M., Akgün A., Anilan T., Sünnetci M.O., Anılan T., Kul Yahşi B., (2019), Modelling of the landslide-induced impulse waves in the Artvin Dam reservoir by empirical approach and 3D numerical simulation, Engineering Geology, 249, 112-128.

Ertunç A., Çetin H., (1999), The geological problems of the large dams constructed on the Euphrates River (Turkey), Engineering Geolology, 51, 167-182. 
Fritz H.M., (2002), Initial phase of landslide generated impulse waves, Mitteilungen 178, Versuchsanstalt für Wasserbau, Hydrologie und Glaziologie (VAW), ETH, Zurich.

Fritz H.M., Hager W.H., Minor H.E., (2004), Near field characteristics of landslide generated impulse waves, Journal of Waterway, Port, Coastal, and Ocean Engineering, 130, 287-302.

Gabl R., Seibl J., Gems B., Aufleger M., (2015), 3-D numerical approach to simulate the overtopping volume caused by an impulse wave comparable to avalanche impact in a reservoir, Natural Hazards and Earth System Science, 15, 2617-2630.

Grilli S.T., Vogelmann S., Watts, P., (2002), Development of a 3D numerical wave tank for modeling tsunami generation by underwater landslides, Engineering Analysis with Boundary Elements, 26, 301-313.

Güven İ.H., (1993), Doğu Pontidlerin Jeolojisi ve 1/250.000 Ölçekli Kompilasyonu, MTA Yayınları, Ankara.

Heller V., (2007), Landslide generated impulse waves - Prediction of near field characteristics, Doktora Tezi, ETH, Zurich.

Heller V., Hager W.H., Minor H.E., (2009), Landslide generated impulse waves in reservoirs - Basics and computation, Mitteilungen 211, Versuchsanstalt für Wasserbau, Hydrologie und Glaziologie (VAW), Zurich, ss.172.

Heller V., Hager W.H., Minor H.E., (2008), Scale effects in subaerial landslide generated impulse waves, Experiments in Fluids, 44, 691-703.

Huber A. Hager, W.H., (1997), Forecasting impulse waves in reservoirs, in: Transactions of The International Congress on Large Dams, 1, 993-1006.

Hughes S.A., (1993), Physical Models and Laboratory Techniques in Coastal Engineering, World Scientific, Singapore, 588 ss.

Kaczmarek H., Tyszkowski S., Banach M., (2015), Landslide development at the shores of a dam reservoir (Włoctawek, Poland), based on 40 years of research, Environmental Earth Sciences, 74, 4247-4259.

Körner H.J., (1976), Reichweite und Geschwindigkeit von Bergstürzen und Fliessschneelawinen, Rock Mechanics, 8, $225-256$.

Montagna F., Bellotti G., Risio M.D., (2011), 3D numerical modeling of landslide-generated tsunamis around a conical island, Natural Hazards, 58, 591-608.

Müller D.R., (1995), Auflaufen und Überschwappen von Impulswellen an Talsperren, Mitteilungen 137, Versuchsanstalt für Wasserbau, Hydrologie und Glaziologie (VAW), Zurich, ss. 297.

Noda E.K., (1970), Water waves generated by landslides, Journal of the Waterways, Harbors and Coastal Engineering Division, 96 , 835-855.

Özsayar T., Pelin S., Gedikoğlu, A., (1981), Doğu Pontidler'de Kretase, Karadeniz Teknik Üniversitesi Yerbilimleri Dergisi, 2, 65114.

Panizzo A., De Girolamo P., Petaccia A., (2005), Forecasting impulse waves generated by subaerial landslides. Journal of Geophysical Research, 110, 1-23.

Quecedo M., Pastor M., Herreros M.I., (2004), Numerical modelling of impulse wave generated by fast landslides, International Journal for Numerical Methods in Engineering, 59, 633-656.

Ramsden J.D., (1996), Forces on a vertical wall due to long waves, bores, and dry-bed surges, Journal of Waterway, Port, Coastal, and Ocean Engineering, 122, 134-141.

Riemer W., (1995), Landslides and reservoirs, Proceedings 6th International Symposium on Landslides içinde, (Bell, D.H. Ed.), Balkema Publishers, ss. 213-224.

Synolakis C.E., (1987), The runup of solitary waves, Journal of Fluid Mechanics, 185: 523-545

Yin Y.P., Huang B.L., Chen X.T., Liu G.N., Wang S.C., (2015), Numerical analysis of wave generated by the Qianjiangping landslide in Three Gorges Reservoir, China, Landslides, 12, 355-64.

Zhang T., Yan E., Cheng J., Zheng Y., (2010), Mechanism of reservoir water in the deformation of Hefeng landslide, Journal of Earth Sciences, 21, 870-875. 